\title{
COMPARATIVE EVALUATION OF ACCURACY OF RECORDING BLOOD PRESSURE EITHER BY AUTOMATED OSCILLOMETRIC METHOD OR BY SPHYGMOMANOMETER IN BOTH NORMOTENSIVE AND HYPERTENSIVE PATIENTS - A PROSPECTIVE OBSERVATIONAL STUDY
}

\author{
SOBANA ${ }^{1}$, PARTHASARATHY ${ }^{2}$ \\ ${ }^{1}$ Associate Professor, Department of Physiology, Mahatma Gandhi Medical College and Research Institute, Puducherry, India. ${ }^{2}$ Associate \\ Professor, Department of Anesthesiology, Mahatma Gandhi Medical College and Research Institute, Puducherry, India. \\ Email:sobana234@gmail.com \\ Received: 12 August 2017, Revised and Accepted: 30 October 2017
}

\section{ABSTRACT}

Objectives: Automatic devices based on oscillometric principle are widely used for the estimation of blood pressure (BP). Mercury sphygmomanometer mean systolic BP (MSBP) and its derived cuff pressure are the traditional mode of estimation which is a validated and authenticated procedure. Automated machines using oscillometric method are slowly replacing the conventional technique. This study was done to compare the BP recorded by the mercury sphygmomanometer MSBP and the automated technique using oscillometric method automated office BP (AOBP).

Methods: Two hundred subjects aged 40-65 years with mid-arm circumference 27-34 cm were recruited. MSBP and AOBP were recorded adhering to guidelines given by the American Heart Association Joint National Committee. The subjects were divided into two groups as normotensive (Group 1) and hypertensive (Group 2), and statistical analysis was performed.

Results: The mean systolic and diastolic pressures estimated by oscillometric method and sphygmomanometer were calculated and compared with each other by paired $t$-test separately for Groups 1 and 2. In mormotensives (Group 1), the mean systolic pressure MSBP was $114.21 \pm 7.5 \mathrm{mmHg}$ and AOBP was $118.24 \pm 11.0 \mathrm{mmHg}$. The mean diastolic MSBP was $72.1 \pm 3.5 \mathrm{mmHg}$ and AOBP was $76.4 \pm 1.2 \mathrm{mmHg}$. Subjects of Group 2 (hypertensive) showed mean systolic pressure MSBP of $144.42 \pm 18.5 \mathrm{~mm} \mathrm{Hg}$ and AOBP of $159.74 \pm 22 \mathrm{mmHg}$. The mean diastolic MSBP was $87.2 \pm 9.5 \mathrm{mmHg}$ and AOBP was $96.9 \pm 9.2 \mathrm{mmHg}$. In Group 1, the difference was statistically not significant, while in Group 2, comparison by paired $t$-test showed a mean difference of systolic pressure by $15.32 \pm 1.25(\mathrm{p}<0.005)$, and mean difference of diastolic pressure by $8.9 \pm 5.8(\mathrm{p}<0.005)$.

Conclusion: Hence, we conclude that oscillometric pressure recordings by the automated device are closer to manual measurements in normotensives but showed a significant high value in hypertensives. We suggest caution in treating hypertensives with values derived from automated machines only.

Keywords: Blood pressure, Measurement, Sphygmomanometer, Oscillometry.

(C) 2018 The Authors. Published by Innovare Academic Sciences Pvt Ltd. This is an open access article under the CC BY license (http://creativecommons. org/licenses/by/4. 0/) DOI: http://dx.doi.org/10.22159/ajpcr.2018.v11i2.21959

\section{INTRODUCTION}

Global burden of disease study had identified hypertension as one of the highly prevalent ( $20 \%$ in urban and $14 \%$ in rural population) disease leading to cardiovascular mortality and morbidity [1]. It is included in the diseases listed by the WHO to estimate "Daly's disability adjusted life years" a predictor of health and wellness [2]. Early detection of hypertension and appropriate treatment is emphasized by the US Preventive Task Force 2017 [3].

Estimation of blood pressure (BP) in various clinical settings is routinely done by sphygmomanometer [4]. However, considering environmental safety, it is globally recommended to reduce the usage of mercury [5]. Hence, automatic devices have gained more acceptability, and they are slowly replacing sphygmomanometer [6]. They work with the principle of detecting the oscillations in the arterial wall during deflation of the cuff [7]. They have several advantages over the sphygmomanometer such as compliance, reproducibility, technical advancement, feasibility for home, and ambulatory BP measurements [8].

To validate the authenticity of oscillometric devices, studies have been done comparing the BP recorded by sphygmomanometer and automated devices [9]. Clinical trials in healthy subjects showed both values to be concordant and acceptable [10]. Certain wristband devices tend to vary with other methods of detection [11].

However, the accuracy of BP estimation in hypertensives needs a high degree of precision, and studies are so far not done in hypertensive patients. Hence, we had done this study to compare the BP recorded by sphygmomanometer and automated devices in both normotensives and hypertensives.

\section{METHODS}

The study was conducted in a tertiary care center after obtaining the Institutional Ethical Clearance. Informed consent was obtained from the patients.

\section{Inclusion criteria}

Subjects attending the outpatient Department of General Medicine of both sexes and age 40-65 years with mid-arm circumference $27-34 \mathrm{~cm}$ were included in the study. Expecting a change of more than $10 \%$ in values and with the previous studies, a sample size of 126 was adequate.

\section{Exclusion criteria}

Subjects with contraindication for cuff placement, diagnosed as arrhythmias, peripheral arterial disease, critically ill, and hemodynamically unstable subjects were excluded from the study.

\section{Consort diagram}

The BP was recorded by both sphygmomanometer and the automated device which works on oscillometric principle. The same machine was used in all the recordings. The American Heart Association JNC recommendations for BP measurements were strictly adhered [12]. Ten steps of accurate BP measurement, by Kenneth Andersen, were taken as the thumb rule [13]. The recordings were done by a blinded observer trained in the techniques of BP measurement. Apparatus testing and validation were done before the study adhering to the British 


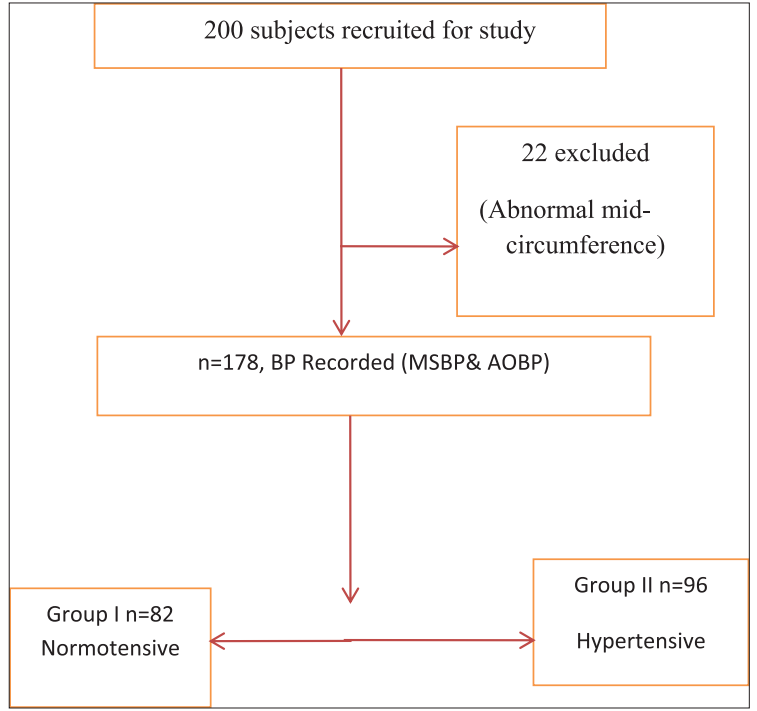

hypertensive society guidelines which states that "out of 5 readings by 2 observers at least $50 \%$ of readings must have difference not more than $5 \mathrm{mmHg}$ [14]." It is recommended to use an ideal cuff with bladder length $80 \%$, and a width $40 \%$ of arm circumference as miscuffing leads to erroneous results [15]. To nullify the factor of miscuffing subjects with mid-arm circumference $27-34 \mathrm{~cm}$ only were recruited for the study [16].

\section{Precautions}

All patients were rested for $5 \mathrm{~min}$, recorded in sitting posture with feet flat on the floor, arm positioned at heart level, avoid talking, and excess tight clothing.

\section{Procedure of mean SBP (MSBP) measurement}

Cuff placement was above the elbow crease according to standard recommendations, and the bell of the stethoscope placed over the palpable pulse at the antecubital fossa. Cuff was inflated until the blood flow stopped and no sounds were heard. The pressure was raised to 30-40 mmHg more than normal BP, and slow deflation $2-3 \mathrm{mmHg} / \mathrm{s}$ was done. The sphygmomanometer reading corresponding to the first rhythmic tapping sound heard when blood begins to flow through the artery indicated SBP. The gauge reading when the cuff pressure drops and sounds fade correspondeds to diastolic pressure.

\section{Procedure of automated office BP (AOBP) measurement}

The automated measurements were done based on the oscillations in the arterial wall during deflation of the cuff. Oscillations begin before SBP and continue below diastolic BP (DBP), maximum during mean arterial pressure, and the SBP and DBP are derived from the empirical formula inbuilt for the device. Measurements were done twice, once with the sphygmomanometer and then after 5 min with the automated oscillometric method. Subjects are divided into two groups based on their previous history of hypertension: Group: 1 - Normotensive and Group: 2 - Hypertensive based on the 2017 AHA JNC guidelines. All patients of Group 2 were known hypertensives on drugs.

\section{RESULTS}

A total of 200 subjects were recruited, and 22 were excluded as they had abnormal mid-arm circumference $(<27 \mathrm{~cm}$ or $>34 \mathrm{~cm})$. Out of the 178 subjects included for study, there were 74 women and 104 men. Data were entered and analyzed using SPSS version 16. Statistical analyses were done separately for Group 1 normotensive and Group 2 hypertensive. The mean systolic and diastolic pressures recorded by both methods were estimated. The mean pressure by sphygmomanometer MSBP and automated machine AOBP was compared using paired $t$-test separately for Groups 1 and 2.
Table 1: Mean SBP and DBP of normotensives

\begin{tabular}{lllll}
\hline Blood pressure & Mean & n & SD & $\begin{array}{l}\text { Standard error } \\
\text { mean }\end{array}$ \\
\hline Systolic manual (MSBP) & 114.21 & 82 & 7.5 & 0.52 \\
Systolic automatic (AOBP) & 118.24 & 82 & 11.0 & 0.36 \\
Diastolic manual (MSBP) & 72.14 & 82 & 3.5 & 1.02 \\
Diastolic automatic (AOBP) & 76.40 & 82 & 1.2 & 0.85 \\
\hline
\end{tabular}

MSBP: Non-invasive cuff pressure, AOBP: Automatic blood pressure (mmHg) Statistically insignificant. MSBP: Mean systolic blood pressure,

AOBP: Automated office blood pressure, SD: Standard deviation, DBP: Diastolic blood pressure

Table 2: Mean SBP and DBP of hypertensive

\begin{tabular}{lllll}
\hline Blood pressure & Mean & n & SD & $\begin{array}{l}\text { Standard } \\
\text { error mean }\end{array}$ \\
\hline Systolic manual (MSBP) & 144.42 & 96 & 18.535 & 1.853 \\
Systolic automatic (AOBP) & 159.74 & 96 & 22.485 & 2.248 \\
Diastolic manual (MSBP) & 87.01 & 96 & 9.543 & 0.954 \\
Diastolic automatic (AOBP) & 96.91 & 96 & 9.769 & 0.977 \\
\hline
\end{tabular}

MSBP: Mean systolic blood pressure, AOBP: Automated office blood pressure

SD: Standard deviation, DBP: Diastolic blood pressure

In Group 1, the mean SBP and DBPs were similar whether we measure manually or with an automated device as shown in Table 1.

When we compared the BP recordings in hypertensives, there was a higher recording of both systolic and diastolic values in the automated machine than in sphygmomanometer (Tables 2 and 3 and Fig. 1).

There were no dropouts in the study, and the study was completed without any untoward events.

\section{DISCUSSION}

Our study results showed that BP recorded manually using sphygmomanometer and by the automated apparatus in normotensives were concordant and within the acceptable range of difference ( $<5 \mathrm{~mm} \mathrm{Hg}$ ) as indicated by the European Society of Hypertension. However, in hypertensives, the two recordings differed widely. SBP showed a mean difference of $15.32 \pm 1.25$ and DBP $8.9 \pm 5.8$, the values being higher in automated machine. It is beyond the accepted range stated by the European Society of Hypertension.

This discrepancy between oscillometric recording when compared to BP estimated by other devices was compared and documented by few researchers done in diverse clinical settings. Xianghu Meng et al. compared BP estimated by Philips Intellivue MP50 monitor with the manual BP recorded. He observed a difference of $>10 \mathrm{mmHg}$ in $>10 \%$ of patients [17]. Lee et al. compared automated BP with invasive arterial pressure recorded from radial and dorsalis pedis arteries in surgical patients [18]. The results were in concordance with ours, as it showed high values of SBP recorded by automated instrument [19]. These results were beyond the standards set by the Association for the Advancement of Medical Instrumentation [20].

A study by van Bergen et al., in their different observation, concluded that automated BP recorded was accurate compared even to the intraarterial pressure [21]. This study was carried out in healthy adults with the majority of normotensives, who in our study also had both readings in the acceptable range. We can assume that, in the normotensives, oscillometric apparatus recordings are accurate and reliable.

The importance of accurate BP estimation is strongly emphasized by recent guidelines based on clinical trials. The Indian guidelines of hypertension based on the Kidney Disease Global Outcome study strictly prohibit BP reduction beyond 130/85 $\mathrm{mmHg}$ considering the consequence of hypotension, especially in the elderly [22]. The report 
Table 3: Comparison of mean MSBP versus AOBP in hypertensive

\begin{tabular}{llllll}
\hline Blood pressure & Mean & SD & Standard error mean & & \multicolumn{2}{c}{ 95\% confidence interval } \\
\cline { 3 - 5 } & & & & Lower & Upper \\
\hline Systolic MSBP versus AOBP & -15.320 & 11.253 & 1.125 & -17.553 & -13.087 \\
Diastolic MSBP versus AOBP & -5.900 & 5.853 & 0.585 & -7.061 & -4.739 \\
\hline
\end{tabular}

MSBP: Non-invasive cuff pressure, AOBP: Automatic blood pressure. MSBP: Mean systolic blood pressure, AOBP: Automated office blood pressure, SD: Standard deviation

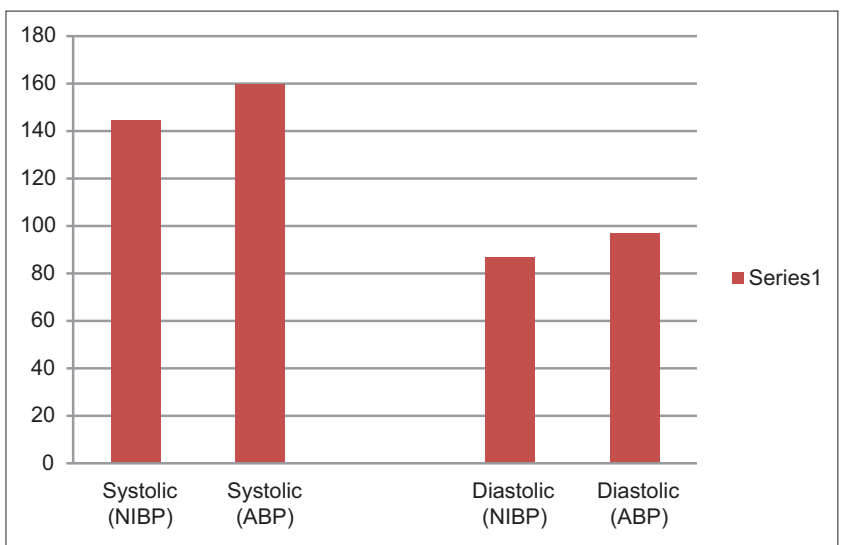

Fig. 1: Comparison of systolic and diastolic pressures (NIBP Vs manual)

of the systolic pressure intervention trial recommends SBP target of $<140 \mathrm{mmHg}$ in patients with high cardiovascular risk. Patients were divided into intensive treatment group (BP target $>120 \mathrm{mmHg}$ ) and standard treatment group (BP target $>140 \mathrm{mmHg}$ ). It concluded that there is a $25 \%$ lower risk of the adverse cardiac outcome in the standard treatment group [23]. Failure to adherence to intake of drug protocol also leads to various complications. Hence, it is important to categorize those patients for prescribing medicines [24].

Automated device is used for BP estimation in day-to-day clinical practice in multiple settings such as outpatient, critical care, and continuous BP monitoring. Critical decision and pharmacological interventions are done based on this parameter $[25,26]$. We observed from our results that there is a higher value of recorded BP with automated device, especially in hypertensives. Hence, if treatment is based on a false high value, there is a chance of inadvertent use of antihypertensive, leading to serious adverse effects such as hypotension which can be disastrous, especially in the elderly.

\section{CONCLUSION}

We conclude that BP recordings of both systolic and diastolic values were higher when measured with an automated device than the MSBP mercury sphygmomanometer in hypertensives. The values were similar in normotensives. We suggest that we should be extra cautious while prescribing drugs to hypertension with measurements on automated devices alone.

\section{REFERENCES}

1. Murray CJ, Lopez AD. Global mortality, disability, and the contribution of risk factors: Global burden of disease study. Lancet 1997;349:1436-42

2. Arnesen T, Nord E. The value of DALY life: problems with ethics and validity of disability adjusted life years. BMJ 1999;319:1423-5.

3. Catalona WJ, D'Amico AV, Fitzgibbons WF, Kosoko-Lasaki O, Leslie SW, Lynch HT, et al. What the U.S. Preventive services task force missed in its prostate cancer screening recommendation. Ann Intern Med 2012;157:137-8.

4. Mengden T, Binswanger B, Grüne S, Spühler T, Weisser B, Vetter W. Are mercury sphygmomanometers obsolete? Schweiz Rundsch Med
Prax 1992;81:96-102.

5. Jegatheswaran J, Ruzicka M, Hiremath S, Edwards C. Are automated blood pressure monitors comparable to ambulatory blood pressure monitors? A systematic review and meta-analysis. Can J Cardiol 2017:33:644-52.

6. Littler WA, Komsuoglu B. Which is the most accurate method of measuring blood pressure? Am Heart J 1989;117:723-8.

7. Treskes RW, Wolterbeek R, van der Velde ET, Eindhoven DC, Schalij MJ. Comparison of the diagnostic accuracy of four smartphonecompatible blood pressure monitors in post-myocardial infarction patients. J Telemed Telecare 2017:1357633X17704092.

8. Mattu GS, Heran BS, Wright JM. Comparison of the automated noninvasive oscillometric blood pressure monitor (BpTRU) with the auscultatory mercury sphygmomanometer in a paediatric population. Blood Press Monit 2004;9:39-45.

9. Herpin D, Vaisse B. Non-invasive ambulatory recording of blood pressure. Current data. Ann Cardiol Angeiol (Paris) 1989;38:103-8.

10. Rinfret F, Cloutier L, L'Archevêque H, Gauthier M, Laskine M, Larochelle P, et al. The gap between manual and automated office blood pressure measurements results at a hypertension clinic. Can J Cardiol 2017;33:653-7.

11. Taxak S, Amitchawla, Poojabihani, Sarlahooda, Geetaahlawat, Anandasha, et al. Wrist blood pressure-can it be an acceptable method of monitoring bloind pressure in perioperative set up.Int J pharm pharm Sci 2013;5:161-2

12. Pickering TG. Principles and techniques of blood pressure measurement. Cardiol Clin 2002;20:207-23

13. Myers MG, Godwin M, Dawes M, Kiss A, Tobe SW, Kaczorowski J. Measurement of blood pressure in the office. Hypertension 2010;55:195-200.

14. O'Brien E, Pickering T, Asmar R, Myers M, Parati G, Staessen J, et al. Working group on blood pressure monitoring of the European society of hypertension international protocol for validation of blood pressure measuring devices in adults. Blood Press Monit 2002;7:3-17.

15. Chobanian AV, Bakris GL, Black HR, Cushman WC, Green LA, Izzo JL Jr, et al. The seventh report of the joint national committee on prevention, detection, evaluation, and treatment of high blood pressure: The JNC $7^{\text {th }}$ Report. JAMA 2003;289:2560-71.

16. Maxwell MH, Waks AU, Schroth PC, Karam M, Dornfeld LP. Error in blood-pressure measurement due to incorrect cuff size in obese patients. Lancet 1982;2:33-6.

17. Meng X, Zang G, Fan L, Zheng L, Dai J, Wang X, et al. Non-invasive monitoring of blood pressure using the Philips intellivue MP50 monitor cannot replace invasive blood pressure techniques in surgery patients under general anesthesia. Exp Ther Med 2013;6:9-14.

18. Lee JH, Kim JM, Ahn KR, Kim CS, Kang KS, Chung JH, et al. Study for the discrepancy of arterial blood pressure in accordance with method, age, body part of measurement during general anesthesia using sevoflurane. Korean J Anesthesiol 2011;60:323-8

19. Darovic GO, Vanriper J, Vanriper S. Arterial pressure monitoring. Hemodynamic Monitoring: Invasive and Non-Invasive Clinical Application. Philadelphia, PA: Saunders; 1995. p. 177-210.

20. O'Brien E, Waeber B, Parati G, Staessen J, Myers MG. Blood pressure measuring devices: Recommendations of the European society of hypertension. BMJ Br Med J 2001;322:531-6.

21. Van Bergen FH, Weatherhead DS, Treloar AE, Dobkin AB, Buckley JJ. Comparison of indirect and direct methods of measuring arterial blood pressure. Circulation 1954;10:481-90.

22. Levey AS, Eckardt KU, Tsukamoto Y, Levin A, Coresh J, Rossert J, et al. Definition and classification of chronic kidney disease: a position statement from Kidney Disease: Improving Global Outcomes (KDIGO). Kidney Int 2005:67:2089-100.

23. Zion MM, Balkin J, Rosenmann D, Goldbourt U, Reicher-Reiss H, Kaplinsky E, et al. Use of pulmonary artery catheters in patients with acute myocardial infarction. Analysis of experience in 5,841 patients in 
the SPRINT Registry. SPRINT Study Group. Chest 1990;98:1331-5.

24. Amal K, Syed A. Elevated blood pressure among patients with hypertension in general hospital of Penang Malaysia-does poor adherence matter? Int J Pharm Pharm Sci 2010;2:29-35.

25. Heinemann M, Sellick K, Rickard C, Reynolds P, McGrail M.
Automated versus manual blood pressure measurement: A randomized crossover trial. Int J Nurs Pract 2008;14:296-302.

26. Bottini PB, Carr AA, Prisant LM, Rhoades RB. Variability and similarity of manual office and automated blood pressures. J Clin Pharmacol 1992;32:614-9. 